\title{
Diffuse Pulmonary Amyloidosis with Monoclonal IgG-kappa Gammopathy
}

\author{
Shuuji Takashi, Tomonobu KoIzumi, Yoshitaka Yamazaki, Muneharu HaYasaka, \\ Keishi Kubo, Morie SeKiguchi and Takayuki HondA*
}

\begin{abstract}
A 62-year-old female with diffuse pulmonary amyloidosis developed abnormal radiographic findings while under observation for hyperimmunoglobulinemia over a ten-year period. Serum immunoglobulin $\mathrm{G}(\mathrm{IgG})$ was elevated $(4,620 \mathrm{mg} / \mathrm{dl})$, and associated with monoclonal gammopathy (M protein) of the kappa type, but no evident abnormalities were apparent in bone marrow. Chest radiograph and computed tomography showed a diffuse reticulonodular shadow in the bilateral lung. Thoracoscopic lung biopsy specimen revealed depositions of amyloid in the bronchus and pulmonary vessel. We emphasize that diffuse pulmonary amyloidosis should be considered a possible diagnosis in the presence of monoclonal immunoglobulin.
\end{abstract}

(Internal Medicine 36: 357-359, 1997)

Key words: thoracoscopic lung biopsy, light chain, hyperimmunoglobulinemia, interstitial pulmonary fibrosis

\section{Introduction}

Diffuse pulmonary amyloidosis is one form of pulmonary deposition of amyloid. This type of pulmonary amyloidosis usually occurs in association with primary amyloidosis, and is considered to be the least common form of pulmonary amyloidosis (1-8). Several pathological studies have revealed that pulmonary involvement with amyloid in patients with primary amyloidosis is more frequent than has been suspected clinically (1-5): Clinical cases which produced respiratory symptoms without cardiac amyloidosis-related clinical manifestation are rare. We present a case of diffuse alveolar septal amyloidosis which shows clinical significance. The patient has been observed for over ten years for an elevated level of immunoglobulin (Ig), and has developed abnormal radiographic findings.

\section{Case Report}

A 62-year-old nonsmoking female was referred to our hospital on December 1994 because of cough and sputum. She underwent left lower lobectomy for pseudolymphoma in 1982, and was diagnosed with hypergammaglobulinemia at that time. However, repeated examinations of bone marrow aspirations showed no abnormal findings. The values of $\gamma$-globulin (IgA; 464-771 mg/dl, IgG; 3,311-4,795 mg/dl) have been stable since the operation. Physical examinations revealed no abnormal findings, but chest radiograph showed an interstitial shadow on bilateral lungs. Her symptoms and chest radiographic findings did not improve. She was admitted to our hospital on July 14, 1995 for further examination. Laboratory data on admission are summarized in Table 1. Hematological findings revealed a slightly decreased level of hemoglobin $(10.9 \mathrm{~g} / \mathrm{dl})$. Blood chemical analysis included; total protein, $9.8 \mathrm{~g} / \mathrm{dl}$, (albumin; $39.8 \%, 3.6 \mathrm{~g} / \mathrm{dl}, \alpha_{1}$-Globulin; $1.8 \%, \alpha_{2}$-Globulin; $7.0 \%, \beta-$ globulin; $14.2 \%$ and $\gamma$-Globulin; $37.2 \%$ with monoclonal protein). Serum Ig levels were IgA; $753 \mathrm{mg} / \mathrm{dl}, \mathrm{IgG} ; 4,620 \mathrm{mg} / \mathrm{dl}$ with monoclonal kappa type of IgG. Erythrocyte sedimentation rate was $7 \mathrm{~mm} / \mathrm{h}$, and C-reactive protein was $0.12 \mathrm{mg} / \mathrm{dl}$. Urinary Bence-Jones protein was negative. Electrocardiogram and echocardiography showed no abnormal findings. Pulmonary function test demonstrated a slight restrictive and obstructive pattern of disturbance \{total lung capacity (TLC); $2.70 l$, vital capacity (VC); $1.81 l, \% \mathrm{VC} ; 77.7 \%$, forced expiratory volume in one second $\left.\left(\mathrm{FEV}_{1.0}\right) ; 1.13 l, \mathrm{FEV}_{1.0 \%} ; 64.8 \%\right\}$ with mild decreased carbon monoxide diffusion capacity (\%Dlco; $75.2 \%$ ). Arterial blood gas analysis showed a normal partial oxygen tension $\left(\mathrm{Po}_{2} ; 87.6\right.$ torr, $\mathrm{PcO}_{2} ; 38.8$ torr). Analysis of bronchoalveolar lavage fluid demonstrated normal cell count and differential cell counts (recovery rate; $68 \%$, total cell count; $2.19 \times 10^{5} / \mathrm{ml}$, macrophages; $87 \%$, lymphocytes; $11 \%$,

From the First Department of Internal Medicine and *the Laboratory Medicine, Shinshu University School of Medicine, Matsumoto

Received for publication August 16, 1996; Accepted for publication February 6, 1997

Reprint requests should be addressed to Dr. Shuuji Takashi, the First Department of Internal Medicine, Shinshu University School of Medicine, 3-1-1 Asahi, Matsumoto 390 
Table 1. Laboratory Data on Admission

\begin{tabular}{lrlr}
\hline Hematology & & ZTT & $17.2 \mathrm{KU}$ \\
White blood cells & $3,680 / \mathrm{mm}^{3}$ & TTT & $0.2 \mathrm{KU}$ \\
Red blood cells & $366 \times 10^{4} / \mathrm{mm}^{3}$ & Lactic dehydrogenase & $160 \mathrm{IU} / l$ \\
Hemoglobin & $10.9 \mathrm{~g} / \mathrm{dl}$ & Aspartate aminotransferase & $18 \mathrm{IU} / l$ \\
Hematocrit & $32.9 \%$ & Alanine aminotransferase & $10 \mathrm{IU} / l$ \\
Platelet & $22.7 \times 10^{4} / \mathrm{mm}^{3}$ & Alkaline phosphatase & $151 \mathrm{IU} / l$ \\
& & $\gamma$-Glutamyl transferase & $11 \mathrm{IU} / l$ \\
Blood chemistry & & Creatine phosphokinase & $219 \mathrm{IU} / l$ \\
Total protein & $9.8 \mathrm{~g} / \mathrm{dl}$ & Amylase & $62 \mathrm{IU} / l$ \\
Albumin & $1.8 \%$ & $\mathrm{Cl}$ & $141 \mathrm{mEq} / l$ \\
$\alpha_{1}$-globulin & $7.0 \%$ & $\mathrm{~K}$ & $107 \mathrm{mEq} / l$ \\
$\alpha_{2}$-globulin & $14.2 \%$ & $\mathrm{Ca}$ & $3.4 \mathrm{mEq} / l$ \\
$\beta$ globulin & $37.2 \%$ & & $8.5 \mathrm{mg} / \mathrm{ml}$ \\
$\gamma$ globulin & $12 \mathrm{mg} / \mathrm{dl}$ & Serology & \\
Urea nitrogen & $0.7 \mathrm{mg} / \mathrm{dl}$ & IgA & $753 \mathrm{mg} / \mathrm{dl}$ \\
Creatinine & $3.6 \mathrm{mg} / \mathrm{dl}$ & IgM & $87 \mathrm{mg} / \mathrm{dl}$ \\
Uric acid & $135 \mathrm{mg} / \mathrm{dl}$ & IgG & $4,620 \mathrm{mg} / \mathrm{dl}$ \\
Total cholesterol & $0.6 \mathrm{mg} / \mathrm{dl}$ & $\mathrm{C} \mathrm{reactive} \mathrm{protein}$ & $0.12 \mathrm{mg} / \mathrm{dl}$ \\
Total bilirubin & & Erythrocyte sedimentation rate & $7 \mathrm{~mm} / \mathrm{h}$ \\
& & & \\
\hline
\end{tabular}

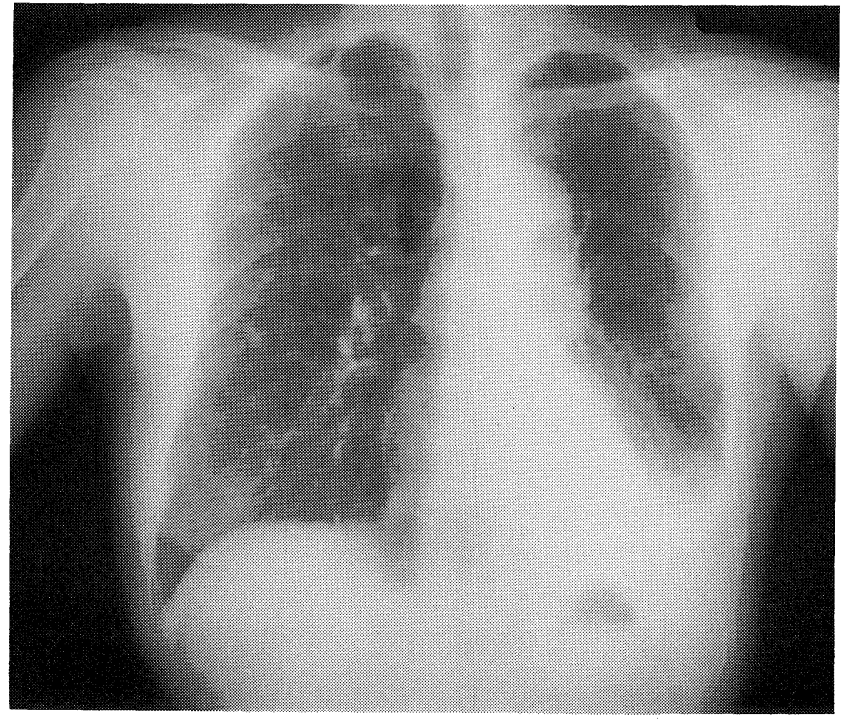

Figure 1. Chest radiograph showed a diffuse reticulonodular shadow in bilateral lung.

neutrophils; $2 \%$, eosinophils; $0 \%$ and CD4/CD8; 1.96). Chest radiograph showed a diffuse reticulonodular shadow in bilateral lungs, and post-lobectomic change in the left lower lung field (Fig. 1). Chest computed tomography (CT) showed multiple small nodular shadows along the bilateral bronchovascular bundle, thickening of interlobular septum and bronchiole, and bronchiectasis (Fig. 2). Bone marrow examination showed no abnormal proliferation of plasma cells.

Thoracoscopic lung biopsy from the right middle (S4) and lower lobes (S8) was performed. Two lung biopsy specimens showed identical histological findings (Fig. 3), and revealed

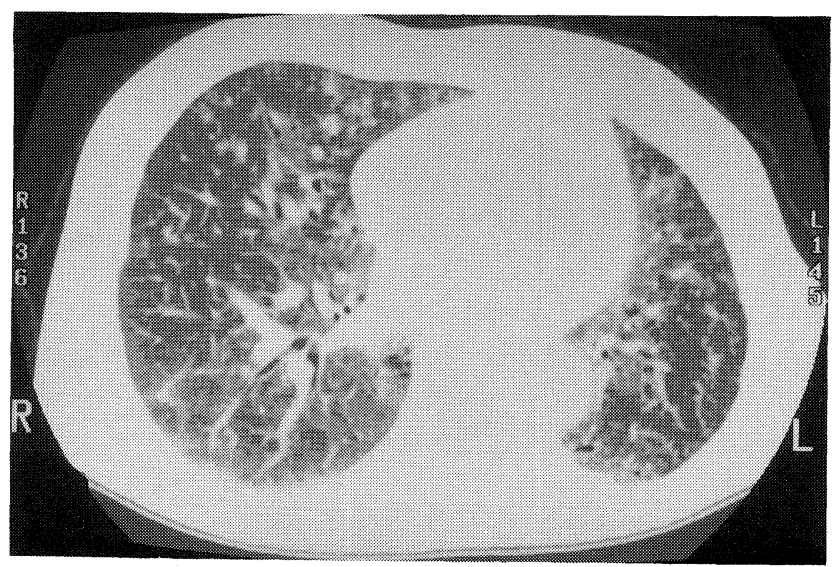

Figure 2. Chest computed tomography revealed multiple nodular shadows along bilateral bronchovascular bundle, and thickening of the interlobular septum and bronchiole.

that the bronchial walls were thickened, an eosinophilic amorphismic substance had invaded the alveolus most prevalently around the bronchus and vessel, and monocytes and giant cells were invasive but no dysplasia was seen. The amorphismic substance was stained by congo red and not digested by potassium permanganate. Thus, it was thought to be an immunoglobulin-derived amyloid (AL protein). Immunohistochemical staining confirmed that it was kappa type, identical to the protein in the serum.

\section{Discussion}

Diffuse parenchymal amyloidosis is usually associated with systemic conditions, such as primary amyloidosis or multiple 


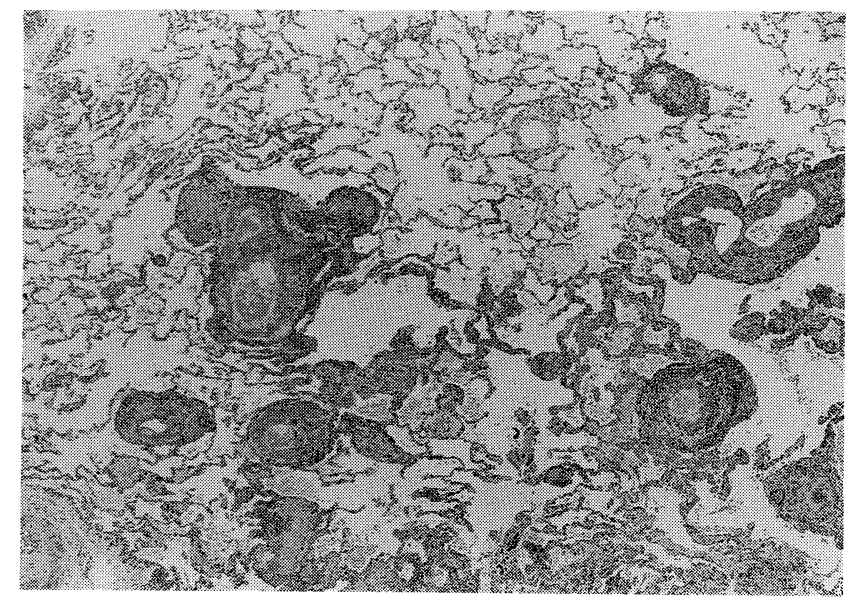

Figure 3. The resected lung specimens showed that an eosinophilic amorphismic substance was deposited around the bronchus and vessel, and the monocytes and giant cells were invasive (HE stain, $\times 40$ ).

myeloma (1-8). The involvement of respiratory tissue is pathologically common in immunoglobulin-derived amyloidosis, but it rarely becomes clinically significant (1-6). Amyloid deposition in the heart and/or kidney has been thought to be a factor in patients with primary amyloidosis, and cardiac or renal function is an important prognostic indicator $(1-4,6,9,10)$. Pulmonary involvement tends to mirror the cardiac manifestations both in frequency and in extent (6), but the evidence of pulmonary amyloidosis is mainly found at autopsy (1-6).

Several authors have described cases with diffuse parenchymal pulmonary amyloidosis who had severe respiratory impairment $(1-6,8)$. These cases were found to have amyloid deposition in the pulmonary interstitial structure, especially in the gas exchange zones. These cases had an unfavorable prognosis with a survival of approximately one year; the death was due to respiratory failure. The histological findings in the present case showed much less deposition of amyloidosis in the gas exchange zone, especially in the pulmonary capillaries, compared to previous reports. The severity of amyloid deposition in pulmonary capillaries is likely to correlate with pulmonary impairment (7). Indeed, the present case showed a normal partial oxygen tension. Furthermore, no remarkable changes in chest radiographic findings and blood gas analysis have been observed since diagnosis over one year ago. Unfortunately, in the present case we can not rule out the possible involvement of amyloidosis in other organs, because of her private reason. The patient remains asymptomatic in related amyloid deposition of the non-pulmonary organs. Based on the clinical course and histological examination of the present case, long-term survival is a possibility.

The present case developed a diffuse radiographic presentation during a ten-year follow-up of hyperimmunoglobulinemia. She had detectable monoclonal immunoglobulin with kappa light chain in the serum, and had a history of lobectomy for pseudolymphoma. There are a few reports in which lymphoma cell was responsible for the deposition of light chain amyloidosis $(11,12)$. We examined the resected lung specimen obtained during the operation for pseudolymphoma, but found no evidence of amyloid deposition. Furthermore, the degree of hyperimmunoglobulin has unchanged even after the resection of pseudolymphoma. Based on these clinical findings, we speculated that the amyloid deposition in the present case was independent of the previously existing pseudolymphoma. The precise mechanisms of amyloidogenesis are still unclear. In addition, we do not know why pulmonary involvement is dominant or clinically significant in our case. Further observations and studies are needed.

In the related literature, there was no correlation between the presence of $\mathrm{M}$ component and a prevalence or pattern of pulmonary amyloidosis. The radiographic abnormalities and clinical features in diffuse parenchymal amyloidosis are frequently confused with those of pulmonary fibrosis. Plasma immunoglobulins are sometimes elevated in patients with pulmonary fibrosis, although the findings are nonspecific. It should be taken into consideration that the diffuse interstitial type of amyloidosis is an important disease which should be distinguished from pulmonary fibrosis, especially in the presence of monoclonal gammopathy.

Acknowledgment: The authors would thank to Dr. Y. Takabayashi and Dr. T. Kaneki for their assistance.

\section{References}

1) Utz JP, Swensen SJ, Gertz MA. Pulmonary amyloidosis, The Mayo Clinic experience from 1980 to 1993. Ann Intern Med 124: 407, 1996.

2) Poh SC, Tjia TS, Seah HC. Primary diffuse alveolar septalamyloidosis. Thorax 30: 186, 1975.

3) Gertz MA, Greipp PR. Clinical aspects of pulmonary amyloidosis. Chest 90: $790,1986$.

4) Cordier JF, Loire R, Brune J. Amyloidosis of the lower respiratory tract; clinical and pathologic features in a series of 21 patients. Chest 90: 827 , 1986.

5) Celli BR, Rubinow A, Cohen AS, Brody JS. Patterns of pulmonary involvement in systemic amyloidosis. Chest 74: 543, 1978.

6) Smith RRL, Hutchins GM, Morre GW, Humphrey RL. Type and distribution of pulmonary parenchymal and vascular amyloid. Correlation with cardiac amyloidosis. Am J Med 66: 96, 1979.

7) Kaneda DJ, Sharma OP. Long-term survival with diffuse interstitial pulmonary amyloidosis. Am J Med 67: 879, 1979.

8) Lewinsohn G, Bruderman I, Bohadana A. Primary diffuse pulmonary amyloidosis with monoclonal gammopathy. Chest 69: 682, 1976.

9) Kyle RA, Greipp PR. Amyloidosis (AL). Clinical and laboratory features in 229 cases. Mayo Clin Proc 58: 665, 1983.

10) Buxbaum TN, Chuba JV, Hellman GC, et al. Monoclonal immunoglobulin deposition disease; light chain and light and heavy chain deposition diseases and their relation to light chain amyloidosis. Clinical features, immunopathology, and molecular analysis. Ann Intern Med 112: 455, 1990.

11) Savage AW, Shareef DS, Maher EJ, Bennett MH, Thomas DJ. Lymphoplasmacytoid lymphoma elaborating lambda chain paraprotein with amyloid deposition in Sjögren's syndrome. Postgrad Med J 65: 323, 1989.

12) Donnelly S, Bourne JT, Levison DA, Doyle DV, Hammond A. Amyloid arthritis associated with IgM kappa lymphoplasmacytoid lymphoma. $\mathrm{Br}$ J Rheumatol 32: 1004, 1993. 